\title{
High Sensitive Graphene Devices for Non-Invasive Early Diagnosis of Hyperthyroidism: A Feasibility Study
}

\author{
Avinash Yadavi, Inayeth Ali², Ahdy Helmy³, Maher Rizkalla',4 \\ ${ }^{1}$ Department of Electrical and Computer Engineering, Purdue School of Engineering and Technology, Indiana \\ University-Purdue University Indianapolis (IUPUI), Indianapolis, IN, USA; ${ }^{2}$ Department of Mechanical and Energy \\ Engineering, Purdue School of Engineering and Technology, Indiana University-Purdue University Indianapolis \\ (IUPUI), Indianapolis, IN, USA; ${ }^{3}$ Richard L. Roudebush Veterans Administration Medical Center, Indianapolis, IN, \\ USA; ${ }^{4}$ Integrated Nanotechnology Development Institute (INDI), Indiana University-Purdue University Indianapolis \\ (IUPUI), Indianapolis, IN, USA
}

Correspondence to: Avinash Yadav, aviyadav@iu.edu

Keywords: Diagnosis, Non-Invasive, GNRFET, Thermography, Ultrasonography, IoT

Received: October 30, $2019 \quad$ Accepted: December 13, $2019 \quad$ Published: December 16, 2019

Copyright $\odot 2019$ by author(s) and Scientific Research Publishing Inc.

This work is licensed under the Creative Commons Attribution International License (CC BY 4.0).

http://creativecommons.org/licenses/by/4.0/

\section{(c) (1) Open Access}

\section{ABSTRACT}

This paper presents a novel approach with Graphene devices that are highly sensitive in detecting IR energy. Current non-imaging techniques like ultrasonography have been proposed for thyroid diagnosis with limitations on ability to detect low-temperature distribution around the hot spot at the starting stage of the thyroid hyperthyroidism. The energy distribution around hotspot is minimal at the beginning stage. This detection may require ultra-high sensitive materials to the IR energy. A computer modeling using COMSOL software shows the thermal energy simulation of a thyroid gland with single or multiple active nodules. Data collection of the energy levels and condition of thyroid in the human body support the work investigated in this study. The study conducted here has shown as low as 0.1 - $5 \mathrm{~mW}$ IR power can be detected based on the Graphene device sensitivity. The paper details the simulation and approach for this non-invasive diagnosis.

\section{INTRODUCTION}

Thyroid gland disorders are impacting nearly five to eight times more women than men. According to the American Thyroid Association, there are 20 million Americans suffering from thyroid diseases. The noticeable thing is that up to 60 percent of those are not aware of it, due to the low level of hyperthyroidism that is hard to be detected with the current technology. The reason for unawareness is the non-diagnosable early stage of the thyroid hyper functioning. One out of eight women develops a thyroid disorder in her lifetime [1], of which a few may be diagnosed after nodules become sizable for sensing de- 
vices to detect. Apart from this, the non-diagnosable effect of hyperthyroidism on pregnant women may increase the risk of miscarriage, preterm delivery, and severe developmental issues with children. Current medical imaging is currently available using ultrasonography or ultrasound scanning for thyroid detection which uses sound to produce pictures of glands and adjusted structure in the neck [2]. It is different from the ionizing radiation techniques such as the X-ray in the sense that there is no radiation exposure to the patient. The scanning is based on the heat generated inside the neck of the patient by the hyperactive nodule due to thyroid disorder. Monitoring the temperature distribution from the outer surface of the neck leads to the thermal analysis of the thyroid. This analysis can be done using various temperature scales and at different values.

\section{ANALOGY OF IMAGING MODALITIES}

Currently, available modalities are specific for different usages in medical diagnostic techniques. $\mathrm{X}$-rays, computed tomography $(\mathrm{CT})$, magnetic resonance imaging (MRI), ultrasound scanning and thermography are considered to be medical diagnostic techniques. X-rays are high energy carrying photons that have enough energy to penetrate metals. Typically, it is used to detect bone disease, dislocations, fractures, infections, and tumors in human body. Computer tomography (CT) scans, however, is more powerful than X-rays. During the process, contrast dyes are often injected to get a better visible structure. It's still of the X-ray nature, appropriate to Orthopedics applications. Magnetic resonance imaging (MRI) is widely used for high resolution mutli cross-section images of bones and muscles. It is also commonly used in brain, spine with joint ligaments, cartilage, and herniated discs. The radio waves generated from this scan cause the tissues in the body to resonate, then the vibrations create a detailed picture by a predefined computer program. Ultrasound imaging uses high-frequency sound waves rather than electromagnetic waves, to create imaging of human organs and tissues. In this case, sound waves reflected from the transducer are converted to electrical signals and this pattern of electrical signals creates a digital image by the computer. The thermography technique is totally based on the heat emission from the surface of any physical object. Contact and non-contact IR sensing are the two approaches followed in thermography, and properly used in medicine. The Non-contact method is the non-invasive approach to diagnose disease by measuring the radiated heat which falls in the infrared region of the spectrum. Comparing various imaging modalities with different parameters implicate their specific usage. Among all the techniques, factors of safety, reliability, and accuracy come first to which modality can be selected. Table 1 gives a summary of the above described imaging techniques.

Table 1. Summary of modalities and applications [1].

\begin{tabular}{ccccc}
\hline Imaging Methods & Application & Features & Limitations & Average Cost \\
\hline X-Rays & Bone disease & Easily available & Radiation & $\$ 300$ \\
CT & Brain disorders & $360^{\circ}$ view & $\begin{array}{c}\text { Injection of iodine } \\
\text { for better definition }\end{array}$ & $\$ 800$ \\
MRI & $\begin{array}{c}\text { Diagnosis of } 4 \mathrm{~mm} \\
\text { thyroid nodule }\end{array}$ & $\begin{array}{c}\text { High resolution } \\
\text { image }\end{array}$ & $\begin{array}{c}\text { Injection require to } \\
\text { get better images }\end{array}$ & $\$ 1000$ \\
Ultrasonography & Soft tissues & $\begin{array}{c}\text { Non-invasive and } \\
\text { better sensitivity }\end{array}$ & Echo noise & $\$ 100$ \\
Thermography & Vascular disease & Non invasive & Small penetration & $\$ 100$ \\
\hline
\end{tabular}




\section{THERMOGRAPHY MATHEMATICAL MODEL OF THE THYROID}

The temperature distribution measured from the surface of the skin is determined by either contact or non-contact infrared thermocouples. Generally, these thermocouples are self-powered infrared (IR) based. Infrared energy is similar to the visible light and follows the basic laws of polarization, reflection, refraction, and diffraction. It falls into the radiation energy with wavelength range of 0.75 to 30 micron, and hence the IR thermocouples can detect a low level of energies. Figure 1 represents the plank's radiation law plot near human body temperature range [3]. This helps to designate the wavelength for a specific energy level. Wien's displacement law states that the maximum wavelength $\left(\lambda_{\max }\right)$ for spectral radiance of black body radiation is given by:

$$
\lambda_{\max }=\frac{b}{T}
$$

where $T$ is absolute temperature and $b$ is wien's displacement constant [4]. Planck-Einstien relation connects the particular photon energy to wavelength lambda $(\lambda)$, and is given by:

$$
E=\frac{h c}{\lambda}
$$

where $h$ is Planck's constant, $c$ is speed of light, and $E$ is corresponding energy.

The degree of thermal contact is an important factor in case of utilizing the contact IR thermocouple, unlike measuring the temperature distribution on the skin using non-invasive thermography used for detection of abnormalities. The thyroid inside the human neck is a center of increased blood flow and increased hormones production, and that why it is considered to be the center of heat production where the temperature is a bit high than the outer surface of human neck, and the morehyperactive its nodules become in disease states the more is the heating emission.

\section{Radiation Energy, W/cm²}

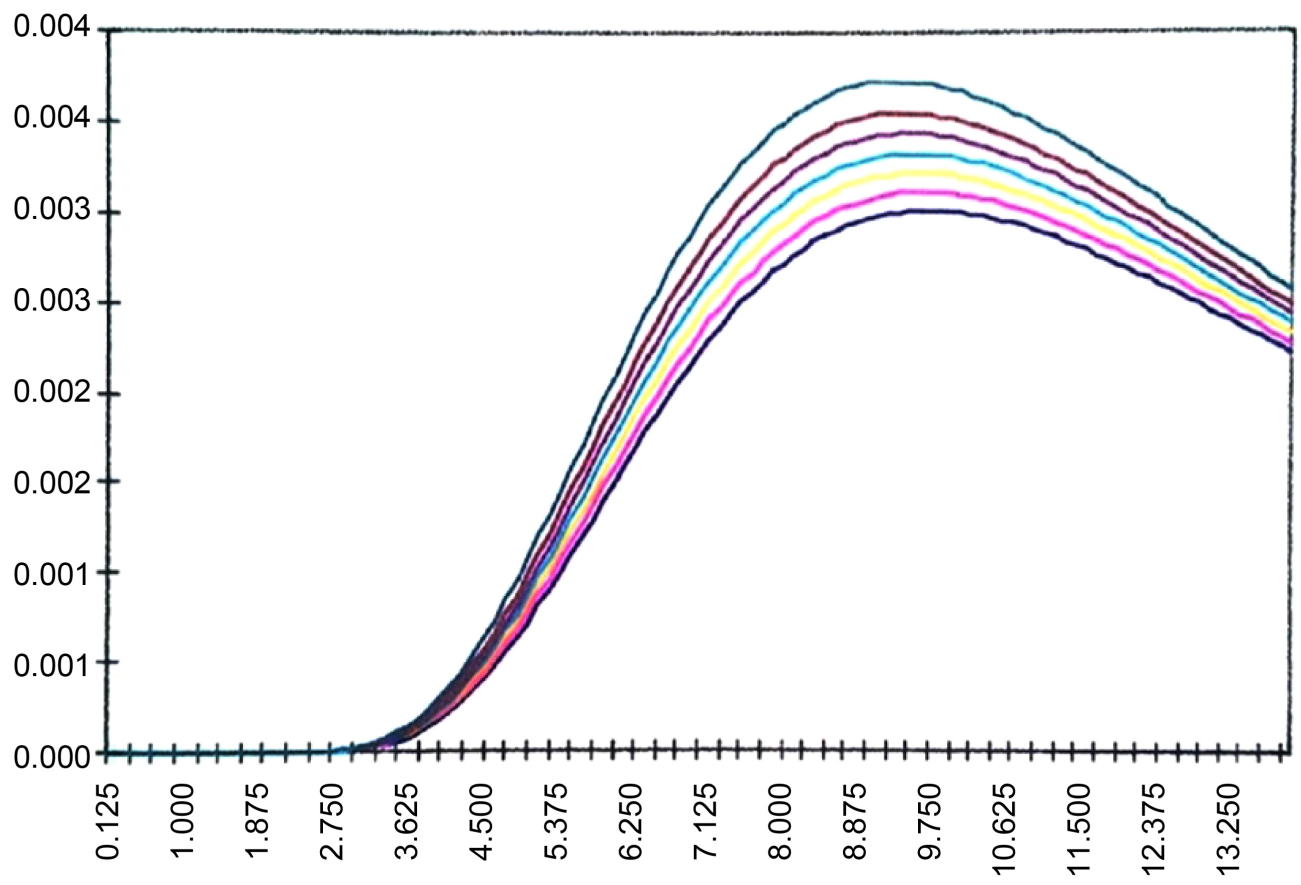

Lambda (microns)

Figure 1. Planck's radiation law plot [3]. 
The sensing device used for this application should determine the deviation of temperature, and is designed by keeping limits of resolution. IR sensors applied should have both accuracy and fast responses. The approach towards diagnosis is based on the calculation of infrared energy emitted by the hyperactive nodules. In the case of multiple nodules, that thyroid disorder is reflected in the emitted energy, and is determined by the individual contribution of each individual nodule. In the measuring process, cooling the neck may be necessary in order to minimize the thermal noise surrounding the thyroid, and this will enhance the temperature distribution contributed from the nodules.

The Wien's displacement law shows that the temperature values near human body core temperature are of wavelength between 9.2 to 9.3 microns. The temperature distribution within the nodules is determined via the numerical solution of the diffusion equations with the proper boundary conditions. The solutions of these equations were done by COMSOL Multi Physics software. The basic diffusion equation used in the temperature distribution is given as:

$$
e_{a} \frac{\partial^{2} u}{\partial t^{2}}+d_{a} \frac{\partial u}{\partial t}+\nabla \cdot(-c \nabla u-\alpha u+\gamma)+\beta \cdot \nabla u+a u=f
$$

where, $\nabla=\left[\frac{\partial}{\partial x}, \frac{\partial}{\partial y}, \frac{\partial}{\partial z}\right], u=f(T)$.

The diffusion constant $c$ and damping coefficient $d_{a}$ is considered to be unity whereas mass coefficient is zero in calculation.

Boundary conditions are specific for each simulation as the outer surface of neck is assumed to be the same and equally distributed over all the exterior surfaces of cubical model. Standard fixedboundary conditions are taken in calculation named as Dirichlet boundary condition which are temperature values for each surface.

\section{PROPOSED NEW SENSORS FOR THIS APPLICATION}

\subsection{Materials}

Ongoing medical technologies use various sensor materials for scanning the human neck. Some of these are semiconductor materials. These materials work on Planck's Radiation Energy plot for various biomedical temperatures. Indium/antimony (InSb), Indium/arsenide (InAs) and Lead selenide (PbSe) were studied with respect to their sensitive, resolution, and other parameters. The study shows how their wavelengths are related to radiation energy [3].

\subsection{Discrete Sensors}

Table 2 gives comparison among various types of discrete sensor available for thermal imaging [3].

\section{PROPOSED MODEL}

As indicated in Table 2, the sensitivity of the existing IR sensor technology is far from meeting the ability to detect a starting nodule (pre-mature) with very low emission energy.

The proposed model consists of graphene sensors arranged in a semi-circular structure in order to scan the neck of the patient. The arrangement of sensors gives the data from the neck. The data is collected and the scanning device array is moved to scan the neck surface to get accurate distribution surrounding the thyroid. This procedure helps to get enough information about the initial state of the thyroid inside the neck. Graphene devices are appropriate for the development stage of thyroid radiates when they carry minimal magnitude of energy. Graphene material and devices are proposed here for their high sensitivity of detection. This will be appropriate for the early non-invasive diagnosis of the hyperthyroidism due to hyperactive thyroid nodule or nodules. The diagram for a proposed measurement system around the neck of a patient and the sensors are arranged in the same fashion is discussed in further section. 
Table 2. Comparisons of various existing thermal devices [3].

\begin{tabular}{|c|c|c|c|c|}
\hline Device & Semiconductor & IR Sensor & Thermistor & Platinum RTD \\
\hline $\begin{array}{l}\text { Measured } \\
\text { Parameter }\end{array}$ & Voltage/Current & $\begin{array}{c}\text { Electromagnetic } \\
\text { waves }\end{array}$ & Resistance & Resistance \\
\hline Advantages & $\begin{array}{l}\text { - Inexpensive } \\
\text { - Liner output } \\
\text { - Low cost } \\
\text { - Ease of use }\end{array}$ & $\begin{array}{l}\text { - } \text { Compact \& } \\
\text { Lightweight } \\
\text { - } \text { Moving object } \\
\text { sensing }\end{array}$ & $\begin{array}{l}\text { - } \text { Cost } \\
\text { - Rugged } \\
\text { - Highly sensitive } \\
\text { - Flexible }\end{array}$ & $\begin{array}{l}\text { - Accuracy } \\
\text { - Linearity } \\
\text { - Stability }\end{array}$ \\
\hline Disadvantages & $\begin{array}{l}\text { - Slow response time } \\
\text { - } \text { Electrical noise } \\
\text { - Accuracy } \\
\text { - Limited application } \\
\text { - Stability for long } \\
\text { term }\end{array}$ & $\begin{array}{l}\text { - Not for gas and } \\
\text { liquid } \\
\text { - } \text { Marginal accuracy } \\
\text { - Expensive } \\
\text { - Ideal medium }\end{array}$ & $\begin{array}{ll}\text { - } & \text { Non-linearity } \\
\text { - } & \text { Moisture failure } \\
\text { - Self-heating } \\
\text { - } \text { Fragile }\end{array}$ & 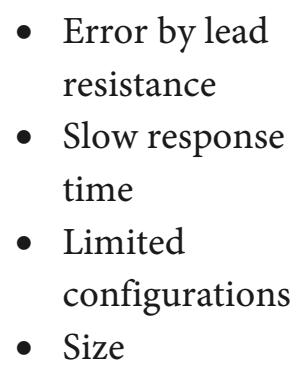 \\
\hline
\end{tabular}

Graphene field effect transistor has analyzed on its maximum IR sensitivity. This analysis is performed by its photoelectric response as a function of voltage. The energy distributed by the thyroid in an early stage is about $0.1-0.5 \mathrm{~mW}$ [5]. So the wavelength of the detecting device should match this energy level in order to successfully scan the neck for getting accurate temperature distribution around the hot spot of the gland. The Graphene infrared sensors have the power to detect very low heat distribution. The device has great potential for low energy detection [6]. Our analysis has been performed to find out the maximum graphene's IR responsivity. For our analysis, typical bias voltages for graphene-based sensor have been chosen [7]. We suggest signaling as the maximum drain-source photocurrent $\left(I_{p h}\right)$ generated under a specific condition, and to noise. The photocurrent has been calculated as the ratio between the voltage acquired and the resistance [8]. This shows the fulfillment of the requirements to detect the low energy values in the case of early hyperthyroidism.

\section{SIMULATION MODE}

The representation of the simulation model related to multiple nodule diagnosis for the human neck is given in Figure 2. This cubical model represents a multi-nodule thyroid with nodules on xy and different activity levels. Due to the different sizes of nodules, the distribution of temperature is considered to be the each nodule. This determines the temperature deviation created by every thyroid nodule inside the neck. The simulations are carried out on various possibilities of nodules to get the proper understanding of temperature distribution. The given model assumed that the temperature of tissues under the skin is considered a little bit higher than the skin temperature. This approach gives us a mapping of temperature distribution towards outer surface of skin from the center.

Before going to multi-nodule model, the deviation of temperature is depicted in Figure 3 for a single nodule condition. Here the cubical structure on the upper yz plane shows a thyroid nodule with a bit higher temperature than the outer skin temperature. The deviation of heat from inside towards outside is shown in the figure. This is a basic temperature distribution mapping which gives rise to the models for multiple thyroids. The boundary conditions are chosen according to the practical situation during the diagnosis which is $36.1^{\circ} \mathrm{C}\left(309.25^{\circ} \mathrm{K}\right)$ for thyroid and $36^{\circ} \mathrm{C}\left(309.15^{\circ} \mathrm{K}\right)$ for the outer skin. 


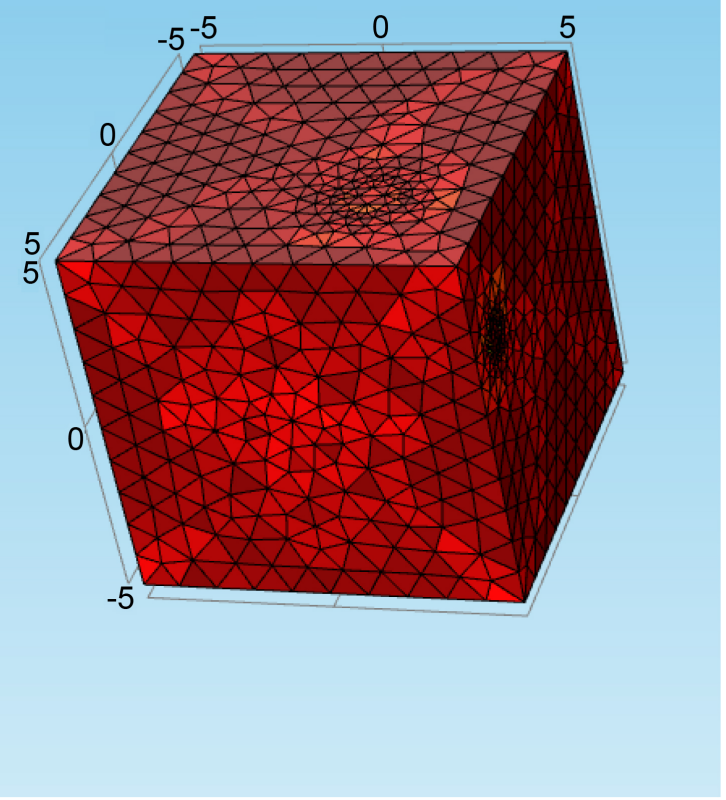

Figure 2. Multi-nodule cubical model.

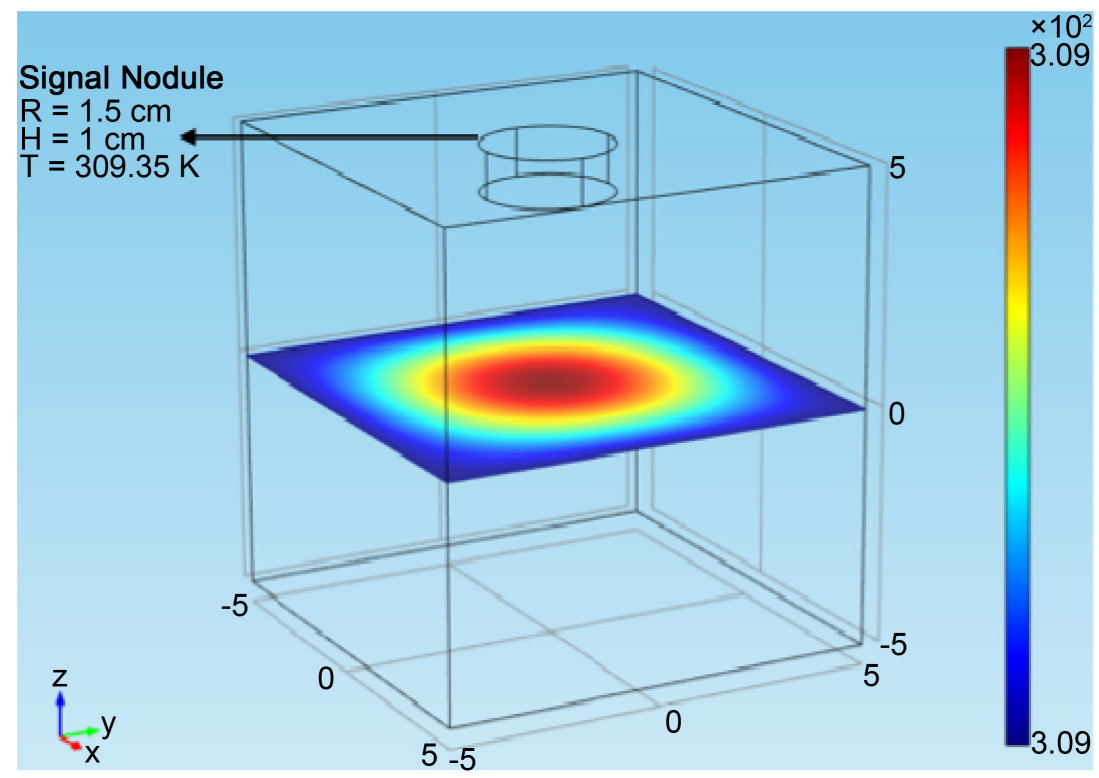

Figure 3. Single nodule $36.1^{\circ} \mathrm{C}$ (sliced view).

The multiple nodule models are studied in three part with different nodule specification for each model:

1) Model-1

This model consists of three nodules on the xy plane of the cube with two nodules of same size and different temperatures. Each cylindrical nodule is of different size. The skin initial temperature was considered as $36^{\circ} \mathrm{C}$ and specification of each nodule is shown in Figure 4.

2) Model-2

This model also consists of three nodules. Each cylindrical nodule is of same size but on the different face of cubical model. Nodule 3 is on the positive xy surface of the model with temperature $36.5^{\circ} \mathrm{C}$ 

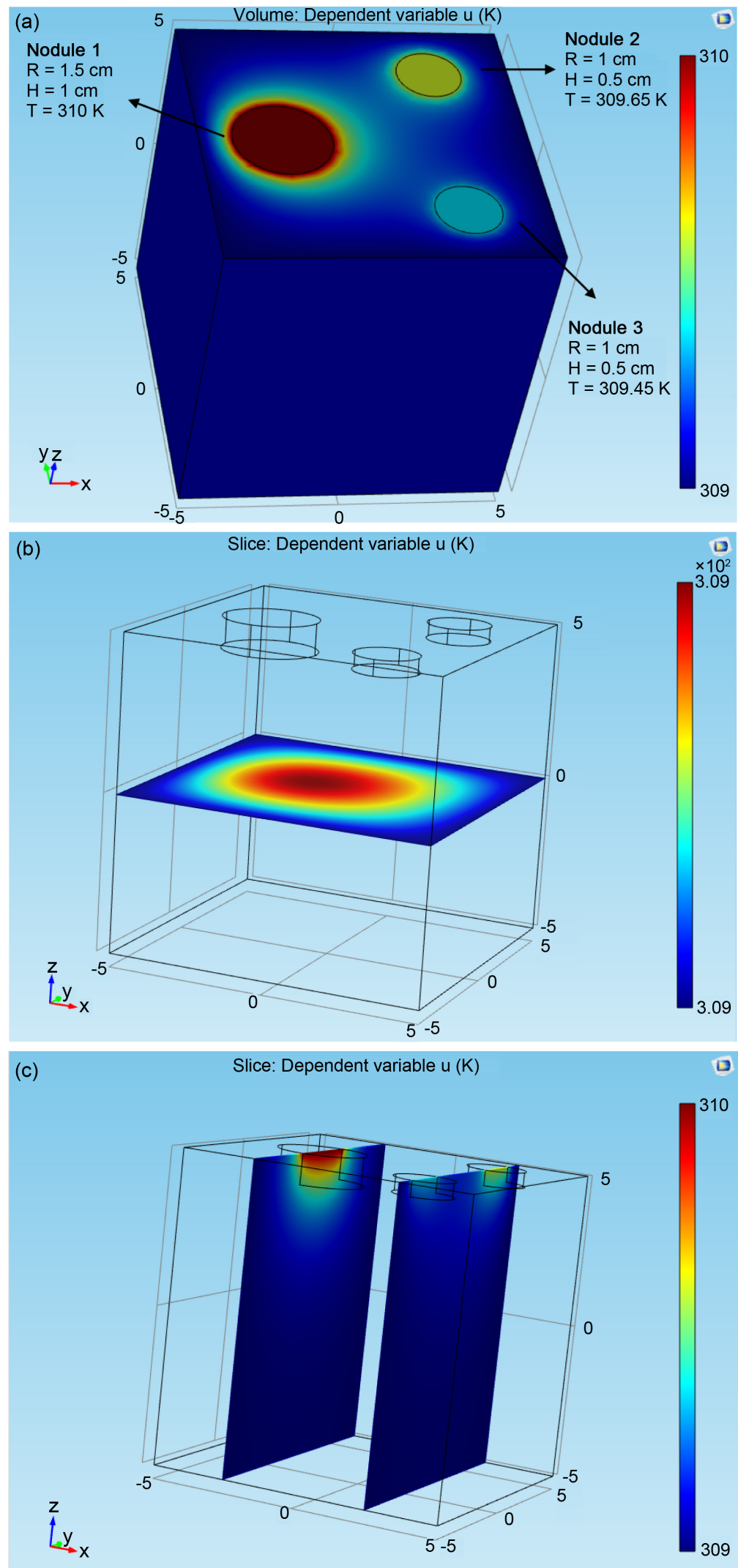

Figure 4. (a) Nodule position I (b) 3D XY sliced view (c) 3D YZ sliced view. 
$\left(309.65^{\circ} \mathrm{K}\right)$ and because of boundary condition on this surface, it's not able to show much temperature deviation in the model. Again, the skin temperature is $36^{\circ} \mathrm{C}$ and specification of each nodule is shown in Figure 5.

3) Model-3

This is another possible model that consists of three nodule. Two of them are on opposite side with different sizes and temperature values. Due to being on the opposite surface, nodule 3 is hidden in Figure 6. The skin temperature is taken at $36.5^{\circ} \mathrm{C}\left(309.65^{\circ} \mathrm{K}\right)$ to see more complexity in the model. Multiple sliced view is captured to study the effect of each nodule from others.
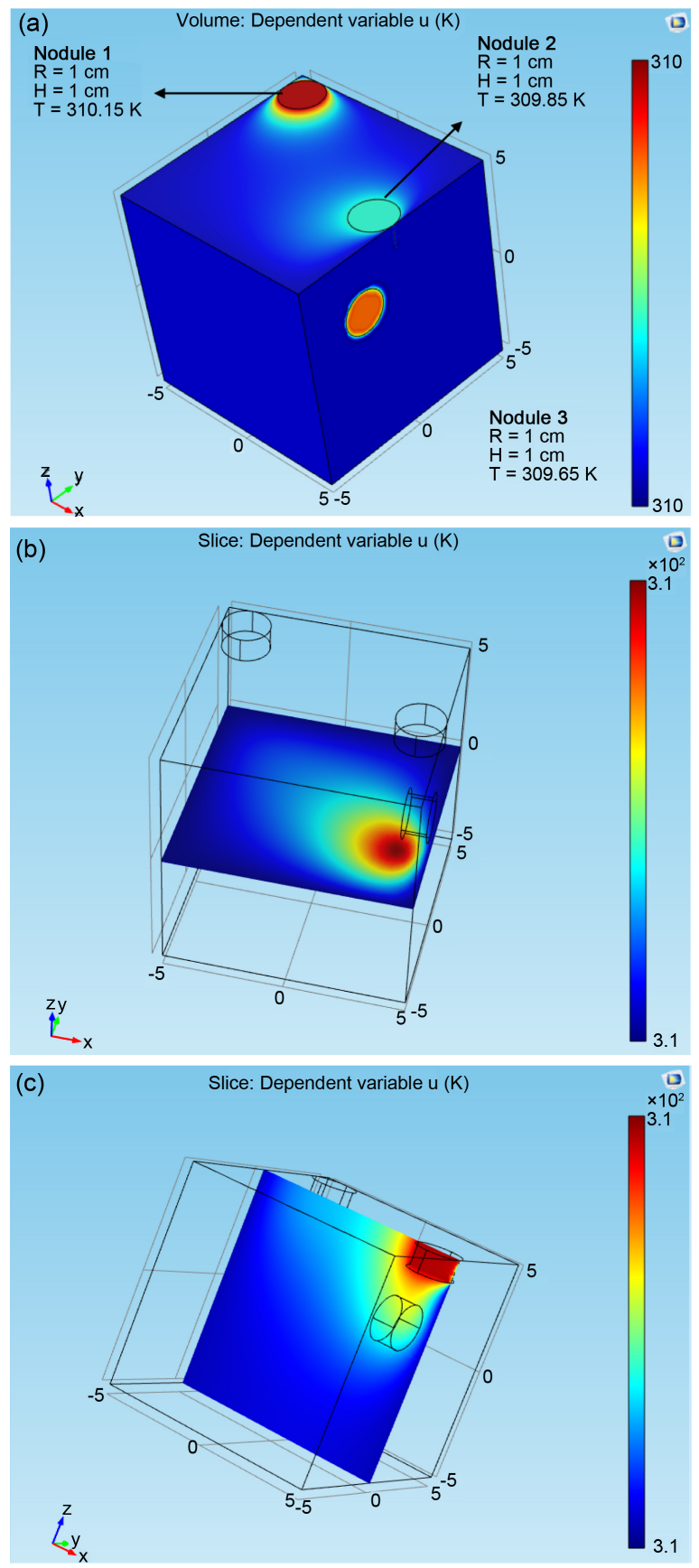

Figure 5. (a) Nodule position II (b) 3D XY sliced view (c) $3 \mathrm{D} \mathrm{XZ}$ sliced view. 

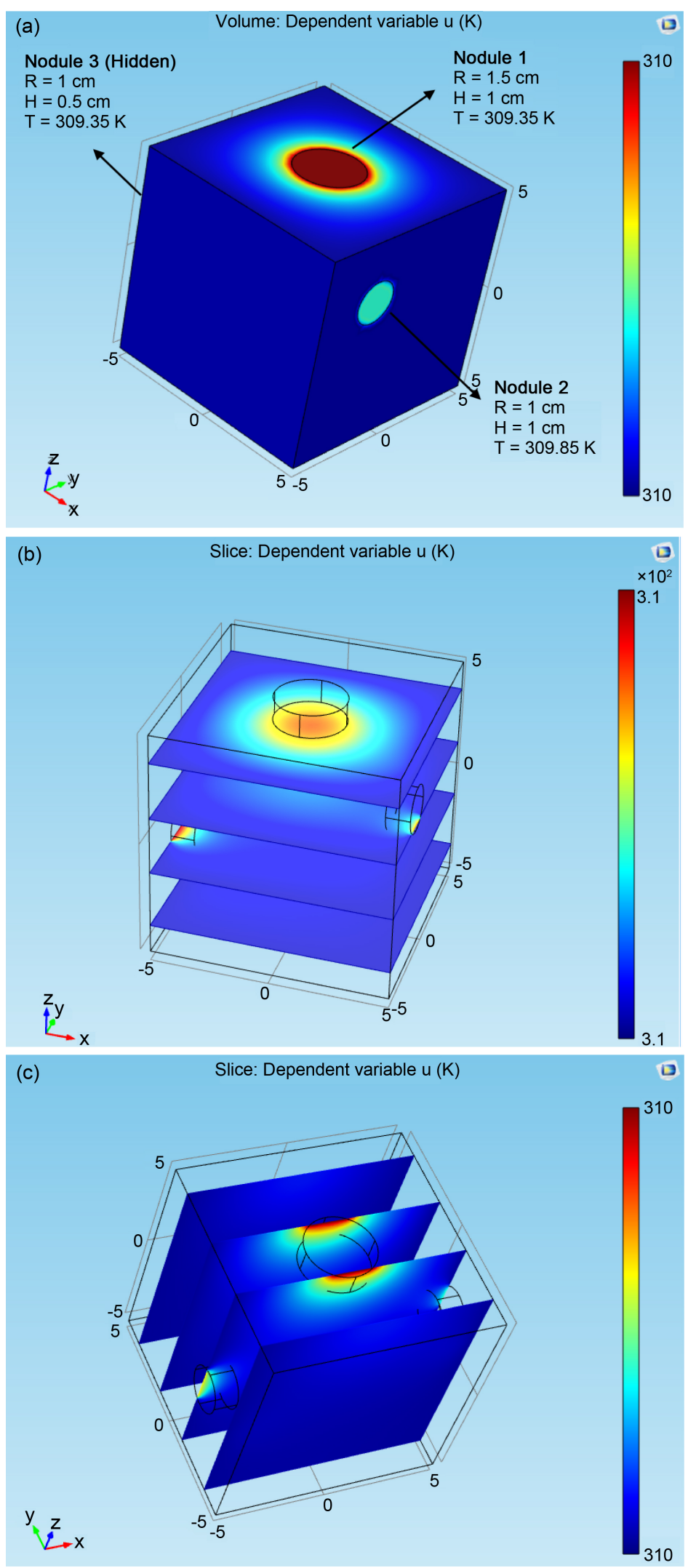

Figure 6. (a) Nodule position III (b) 3D XY multi-sliced view (c) XZ multi-sliced view. 


\section{RESULTS AND DISCUSSION}

The proposed model in Figure 7 uses discrete sensor arrangements made up of graphene infrared sensors which collect data from the thyroid nodules. Upon request, a more sensitive device can be made by changing the material of the sensor. The study conducted in this work will be using discreet sensor arrangements made up of graphene infrared sensors which collect data from the thyroid nodules. Hot-spot inside the patient's neck reflects the hyperactivity of the thyroid and it generates heat in form of the temperature over the neck. A normal patient can be differentiated from thyroid affected patient via reading the temperature profile. Because of excellent thermal properties of graphene, the detection of this minimal energy difference is possible. Since in early stages, the variation in hyperactivity of thyroid is minute, the early diagnosis of thyroid related disease is possible via this graphene-based device [6]. Data collected from the GNRFET sensors are sent to a small signal amplifier. These small signals are converted into large output signals with the factor of gain of the amplifier. The arrangement of these electronic components is shown in Figure 8. Finally, this signal with large amplitude can be recorded and displayed by a data acquisition device.

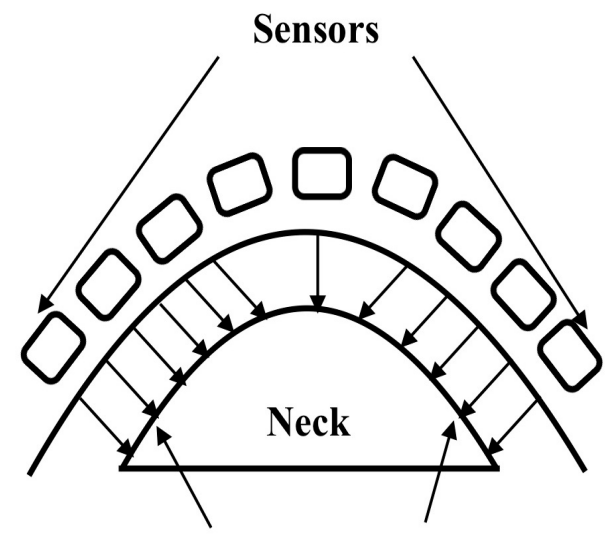

Focused on Neck

Figure 7. Proposed arrangement of sensors.

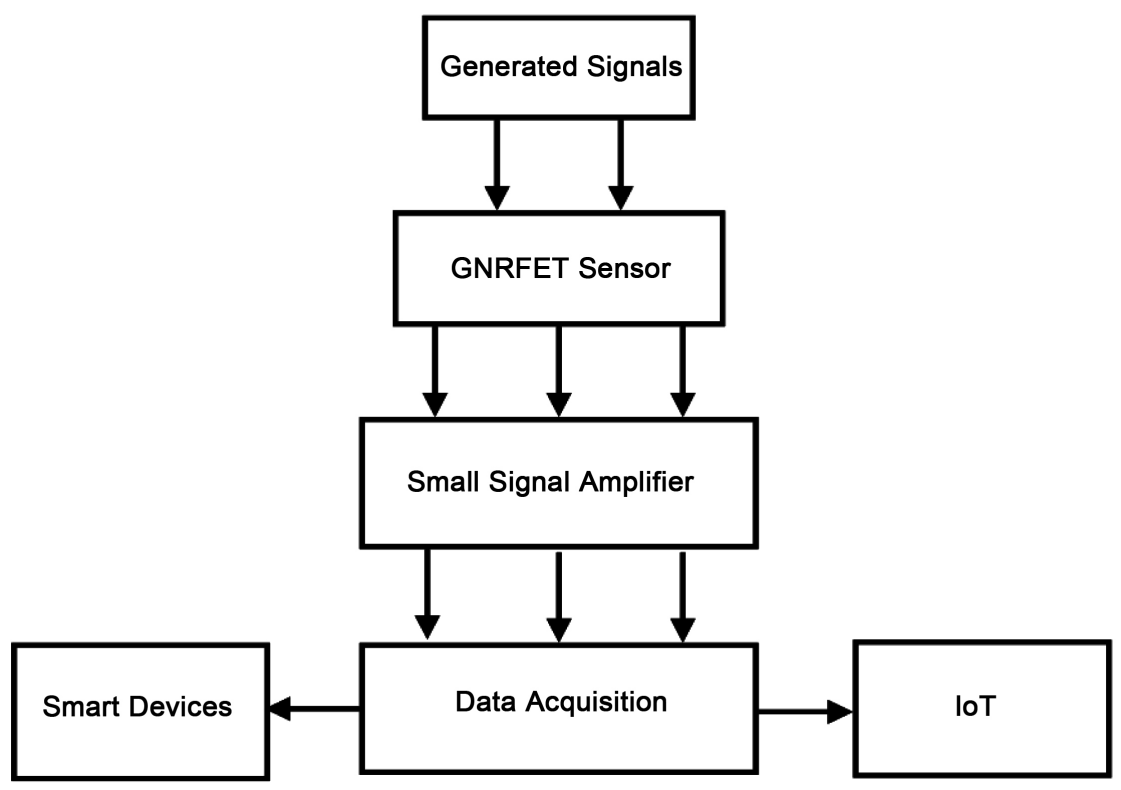

Figure 8. Proposed advance data collection. 
The above arrangement includes smart devices and IoT blocks which is an advance way of thyroid data collection from GNRFET sensors. In this acquisition, we propose the low power bluetooth technology for displaying data on smart devices and thread technology for IoT based data collection.

\section{DISCUSSION AND CONCLUSION}

The prototype of the model is a noninvasive, safe and cost-effective way to detect early thyroid disorders. The proposed IR based imaging approach may advance the current diagnostic techniques into the next level with preventive medicine in this area. This may also save millions of people from missing thyroid disorders or stop the advancement of it. The non-hazardous model can be easily tested on the patient for real time data collection from the neck. For more clarity, we can use a cooling technique to reduce the temperature of the outer surface of the neck to get a perfect understating of the thyroid nodule development. It can be effectively concluded from the simulation that the purpose of the device is successful. Continuous scanning of the human neck will have a better resolution image of every nodule inside the neck. That will be useful to diagnose early stages of thyroid disease and treat it early.

\section{CONFLICTS OF INTEREST}

The authors declare no conflicts of interest regarding the publication of this paper.

\section{REFERENCES}

1. Rizkalla, M.E., Helmy, A.W., Holdmann, M. and Salama, P. (2008) A Novel Approach for a Non-Invasion Diagnostic Technique for Thyroid Glands Using Thermographic System. IEEE Transactions on Biomedical Engineering, Lansing, 8-11 August 2000, 1094-1097.

2. Ashok, L. and Sivanandam, S. (2017) Diagnosis of Thyroid Disorder Using Infrared Thermography. International Conference of Electronics, Communication and Aerospace Technonlogy (ICECA), Coimbatore, 20-22 April 2017, 37-41. https://doi.org/10.1109/ICECA.2017.8203718

3. Helmy, A., Holdmann, M. and Rizkalla, M.E. (2008) Application of Thermography for Non-Invasive Diagnosis of Thyroid Gland Disease. IEEE Transactions on Biomedical Engineering, 55, 1168-1175.

https://doi.org/10.1109/TBME.2008.915731

4. Rizkalla, J., Tilbury, W., Helmy, A., Rizkalla, M., Suryadevara, V.K. and Holdmann, M.M. (2015) Computer Simulation/Practical Models for Human Thyroid Thermographic Imaging. Journal of Biomedical Science and Engineering, 8, 246-256. https://doi.org/10.4236/jbise.2015.84024

5. Haque, A., Islam, R., Alam, N.K. and Islam, R. (2015) Large Signal Performance of Graphene-FET Considering Contact Resistance. Proceedings of International Conference on Electrical Infonnation and Communication Technology, Khulna, 10-12 December 2015, 436-440. https://doi.org/10.1109/EICT.2015.7391992

6. Lv, P., Zhang, X., Deng, W. and Jie, J. (2013) High-Sensitivity and Fast-Response Graphene/Crystalline Silicon Schottky Junction-Based Near-IR Photodetectors. IEEE Electron Device Letter, 34, 1337-1339.

https://doi.org/10.1109/LED.2013.2275169

7. Yu, M., Dong, Z., Yang, J.K.W. and Wang, Q.J. (2016) Room-Temperature Mid-Infrared Photodetector in All-Carbon Graphene Nanoribbon- $\mathrm{C}_{60}$ Hybrid Nanostructure. Optica, 3, 979-984.

https://doi.org/10.1364/OPTICA.3.000979

8. Benfante, A., Giambra, M.A., Pernice, R., Stivala, S., Calandra, E., Parisi, A.and Cino, A.C. (2018) Employing Microwave Graphene Field Effect Transistors for Infrared Radiation Detection. IEEE Photonic Journals, 10, 1-7. tps://doi.org/10.1109/JPHOT.2018.2807923 